University of Nebraska - Lincoln

DigitalCommons@University of Nebraska - Lincoln

Sociology Department, Faculty Publications

Sociology, Department of

January 2008

\title{
Dimensionality of thoughts of death and suicide: Evidence from a study of homeless adolescents
}

\author{
Kevin A. Yoder \\ University of North Texas \\ Les B. Whitbeck \\ University of Nebraska-Lincoln, Iwhitbeck2@unl.edu \\ Dan R. Hoyt \\ University of Nebraska-Lincoln, dhoyt2@unl.edu
}

Follow this and additional works at: https://digitalcommons.unl.edu/sociologyfacpub

Part of the Sociology Commons

Yoder, Kevin A.; Whitbeck, Les B.; and Hoyt, Dan R., "Dimensionality of thoughts of death and suicide: Evidence from a study of homeless adolescents" (2008). Sociology Department, Faculty Publications. 28. https://digitalcommons.unl.edu/sociologyfacpub/28

This Article is brought to you for free and open access by the Sociology, Department of at DigitalCommons@University of Nebraska - Lincoln. It has been accepted for inclusion in Sociology Department, Faculty Publications by an authorized administrator of DigitalCommons@University of Nebraska - Lincoln. 


\title{
Dimensionality of thoughts of death and suicide: Evidence from a study of homeless adolescents
}

\author{
Kevin A. Yoder, ${ }^{*}$ Les B. Whitbeck, ${ }^{\dagger}$ and Dan R. Hoyt ${ }^{\dagger}$ \\ * Department of Sociology, University of North Texas, P.O. Box 311157, Denton, TX 76203- \\ 1157, USA; email: yoder@pacs.unt.edu \\ † Department of Sociology, University of Nebraska-Lincoln, Lincoln, NE 68588, USA
}

\begin{abstract}
This study used data from a sample of 444 homeless adolescents to determine whether thoughts of death and suicide form one construct (unidimensionality) or two distinct but correlated constructs (multi-dimensionality). Thoughts of death and suicide were common in the sample; over two-thirds of the adolescents positively endorsed at least one of the eight death-or suicide-related items. Evidence regarding dimensionality was mixed. Exploratory factor analysis results and similarity coefficients supported one construct; confirmatory factor analysis and external consistency results provided evidence for two constructs. The results were reconciled by considering suicidality as a continuum from thoughts of death to suicidal ideation, suicide attempts, and completed suicide.
\end{abstract}

Keywords: dimensionality, thoughts of death, suicidal ideation, homeless adolescents

\section{Introduction}

Suicide is the third leading cause of death among young people ages 15-24 (Hoyert, Heron, Murphy, \& Kung, 2006), and suicidal ideation and attempts are common during adolescence (Evans, Hawton, Rodham, \& Deeks, 2005). Suicidal ideation represents an extreme form of psychological distress (Schutt, Meschede, \& Rierdan, 1994), which makes it an important quality of life issue for adolescents (Valois, Zullig, Huebner, \& Drane, 2004). However, estimates of the prevalence and incidence of suicidal thoughts vary among studies, in part, because of differences in conceptualization and operationalization (Klimes-Dougan, 1998). In their proposed nomenclature for suicide-related thoughts and behaviors, O'Carroll et 
al. (1996) define suicidal ideation as "any self-reported thoughts of engaging in suicide-related behavior" (p. 247). Some researchers use a broader definition of suicidal ideation that incorporates thoughts of death. For instance, Lewinsohn, Rohde, and Seeley (1996) define suicidal ideation as "thoughts or wishes to be dead or to kill oneself" (p. 26).

Many measures of suicidal ideation among adolescents conform to the definition proposed by $\mathrm{O}^{\prime}$ Carroll et al. (1996) and others include thoughts of death (Goldston, 2000). Extant psychometric evidence in adolescent samples, while scarce, tends to support the inclusion of death-related items in measures of suicidal ideation. Scales that incorporate death-related items generally have Cronbach's alpha-values above 0.80 (e.g., Lewinsohn et al., 1996), and exploratory factor analysis (EFA) results typically indicate that death-and suicide-related items load on the same factor (e.g., Pfeffer, Jiang, \& Kakuma, 2000). Other studies using confirmatory factor analysis (CFA) provide evidence that death-and suicide-related items load on the same factor (e.g., Stewart et al., 2006). These studies, while suggestive, have not explicitly tested whether thoughts of death and suicide form one construct (unidimensionality) or two distinct but correlated constructs (multidimensionality). This study assesses evidence for the dimensionality of thoughts of death and suicide using data from a study of 444 homeless adolescents.

\section{Previous research}

Existing psychometric studies of adolescents that include both death-and suicide- related items have primarily used EFA. For example, in a community sample of older adolescents, Lewinsohn et al. (1996) used four items from the Schedule for Affective Disorders and Schizophrenia for School-Aged Children as well as a four- item screener developed for their project. Each scale contained two death-related items, both had Cronbach's alpha- $(\alpha)$ values above 0.80 , and both had EFA results indicating a one-factor solution.

Moreover, Pinto, Whisman, and McCoy (1997) used a clinical sample of adolescents in an EFA study of 30 items in the Suicidal Ideation Questionnaire. Although they noted that four of the eigenvalues exceeded one, they argued for a one-factor solution because the first eigenvalue accounted for $58.3 \%$ of the total variance. Cronbach's $\alpha$ for all 30 items was 0.97. In addition, Holi et al. (2005) conducted an EFA on the Scale for Suicidal Ideation using an outpatient sample of adolescents. Analyses yielded a three-factor solution in which the death-related item (wish to die) loaded with suicidal ideation items on an "active suicidal desire" factor. Cronbach's $\alpha$ for the ten-item factor was 0.94 .

Two additional studies included items from other constructs in the EFA. First, using a mixed clinical and community sample of children and adolescents, Pfeffer et al. (2000) analyzed the Child-Adolescent Suicidal Potential Index, which included items that measured suicidality, anxiety, impulsivity, depression, and family distress. EFA results provided evidence for a three-factor solution in which the item "want to die" loaded with the suicide-related items in a "suicidal ideation/ acts" factor. Cronbach's $\alpha$ for the six-item factor was 0.86. Second, Tatman, Greene, and Karr (1993) used a high-school sample to assess the factor structure of the Suicide Probability Scale, which included items measuring suicidality, hopelessness, negative self-evaluation, and hostility. EFA analyses pointed to a three-factor solu- 
tion in which three death-related items loaded with five suicide-related items in a "suicidal despair" factor. Cronbach's $\alpha$ for the eight-item factor was 0.90 .

Nevertheless, two studies using EFA found evidence that death- and suiciderelated items load on separate factors. In developing the Suicidal Ideation Questionnaire using school-based samples, Reynolds (1988) reported excellent values of Cronbach's $\alpha$ ( 0.90 and above) when assessing all 30 items. However, EFA results indicated a three-factor solution in which the three death-related items loaded by themselves on one factor. Similar results were obtained for the Suicidal Behaviors Interview (Reynolds, 1990).

Osman et al. $(2002,2003)$ used CFA to investigate the factor structure of the Positive and Negative Suicide Ideation (PANSI) scale. Although the PANSI was developed to measure positive and negative aspects of suicidal ideation (Osman, Gutierrez, Kopper, Barrios, \& Chiros, 1998), it contains seven suicide-related items, two death-related items ("felt so unhappy about your relationship with someone you wished you were dead" and "felt that life was worth living"'), and as noted by Lester (1998), five hopelessness-related items. In their studies of adolescent psychiatric inpatients and high-school students, Osman et al. $(2002,2003)$ found evidence for a two-factor model in which the first death-related item loaded with the suicide-related items and the second death-related item loaded with the hopelessness-related items. Thus, their results provide mixed evidence with respect to the inclusion of death-related items in measures of suicidal ideation.

Three additional studies, while not psychometric, used CFA with death- and suicide-related items and obtained consistent results (Harlow, Newcomb, \& Bentler, 1986; Light, Grube, Madden, \& Gover, 2003; Stewart et al., 2006). First, Harlow et al. (1986) used a community sample of adolescents to test a CFA model that included items measuring depression, self-derogation, purpose in life, substance use, and suicidal ideation. The death-related item loaded on a factor containing four additional suicide-related items. Second, in a study of high-school students, Light et al. (2003) examined a CFA model that included items measuring alcohol use and problems, delinquency, sensation seeking, and suicidality. The suicidality factor had three high-loading variables: (1) affective ideation (three summed death-related items), (2) behavioral ideation (three summed suicide-related items), and (3) suicide attempt (one item). Finally, Stewart et al. (2006) used the four-item measure from Lewinsohn et al. (1996) in a study of Hong Kong and US high-school students ages 14-18. In CFA models estimated separately for each cultural group, all four items loaded highly on a single factor.

On the whole, the results of previous studies tend to support the inclusion of death-related items in measures of suicidal ideation. However, these studies have not explicitly tested whether thoughts of death and suicide form one construct (unidimensionality) or two distinct but correlated constructs (multi-dimensionality). For instance, Cronbach's $\alpha$ gauges the extent to which items are intercorrelated, but it does not provide evidence for dimensionality (Netemeyer, Bearden, \& Sharma, 2003). In addition, while both EFA and CFA provide evidence for dimensionality (Gerbing \& Anderson, 1988; Netemeyer et al., 2003), a more rigorous test of dimensionality includes the calculation of similarity coefficients (SCs) (which measure similarity in correlations among items in the same scale; Steenbergen, 2000) and the assessment of external consistency (which indicates similarity in the correlations of subscales with other variables; Carver, 1989). 
This study assesses evidence for the dimensionality of thoughts of death and suicide by using EFA, SCs, CFA, and measures of external consistency. The data come from a study of 444 homeless adolescents in four Mid-western states. This is an ideal sample to study because both suicidal ideation and its correlates are common among homeless adolescents (Kidd, 2006). The study uses four death-related items, four suicide-related items, and, to assess external consistency, several correlates of suicidal ideation identified in previous research on homeless adolescents (e.g., Kidd, 2006; Rohde, Noell, Ochs, \& Seeley, 2001; Unger, Kipke, Simon, Montgomery, \& Johnson, 1997; Yoder, 1999; Yoder, Hoyt, \& Whitbeck, 1998).

\section{Methods}

\subsection{Participants}

\subsubsection{Interviewers}

The data come from the baseline sample of 444 participants in the Midwest Longitudinal Study of Homeless Adolescents (MLSHA). Full-time interviewers were placed in outreach agencies in eight Mid-western cities (Des Moines, Cedar Rapids, and Iowa City, Iowa; Lincoln and Omaha, Nebraska; St. Louis and Kansas City, Missouri; and Wichita, Kansas). The interviewers held at least a Bachelor's degree, had social service experience, had previously worked with homeless youths, and were already familiar with the local street culture. The interviewers approached potential participants in shelters and in other areas where homeless adolescents hung out, and they were asked to recruit 60 youths. In order to maximize diversity in terms of service use and duration of homelessness, locations were checked repeatedly at various times of the day and days of the week over the course of 1 year.

\subsubsection{Eligibility and protocol}

Youths were eligible to participate in the study if they were ages 16-19 and homeless. Homelessness was defined as living in a shelter, on the street, or on their own (with friends or in a transitional living situation) as a result of being pushed out by - or running away from-their families of origin. Of those who met eligibility criteria, about $90 \%$ agreed to participate. Participants were informed that the study was longitudinal, and the interviewers explained the tracking protocols. The adolescents were assured that refusing to participate, refusing to answer individual questions, or stopping the interview at any time would have no effect on current or future service provision by outreach agencies. The baseline interview was conducted in two parts that were administered within 2 days of each other. The first part contained the bulk of the survey, and the second part consisted of psychiatric diagnostic interviews.

In addition, participants were paid $\$ 25$ at the completion of each part of the interview, and they were interviewed in shelter interview rooms, outreach vans, quiet corners of restaurants, apartments, or outside. All interviews were conducted on laptop computers, and the data were downloaded electronically to a special secure university server. The interviewers underwent 1 week of intensive training for procedures regarding computer-assisted personal interviewing and psychiatric diagnostic interviewing. They then returned to their outreach agen- 
cies and completed several practice interviews with staff members and other respondents ages 20 years or older. After administering the practice interviews, the interviewers returned to the university for a second week of training. Although the practice interviews were checked for accuracy, statistical measures of reliability were not calculated.

\subsubsection{Consent}

The project was approved by the Institutional Review Board (IRB) at the University of Nebraska-Lincoln (\#2001-07-333 FB), and a National Institute of Mental Health Certificate of Confidentiality was obtained to protect the participants if they made statements about potentially illegal activities. Adolescents signed a statement of informed consent, and as mandated by the IRB, they were asked if the interviewers could contact their parents. When parents were contacted, they were asked to provide verbal consent to interview the adolescents, and parental consent was granted in every case. The parents were also asked to participate in a telephone interview. Requiring parental consent did not affect recruitment and retention of participants.

Moreover, when talking to the parents, the interviewers did not disclose specific information about the adolescents. In cases where the parents requested details about the adolescent's location or well-being, the interviewers stated that they had spoken to the adolescent, indicated that the adolescent was all right, and offered to relay the parent's inquiry to the adolescent. Among adolescents living in shelters, the interviewers followed shelter policies of parental permission for placement and guidelines concerning in loco parentis for granting such permissions. These policies were always based on state laws. In the few cases where adolescents were under 18 years old, not in a shelter, and refused permission to contact their parents, the adolescents were treated as emancipated minors according to National Institutes of Health guidelines (US Department of Health and Human Services, 2001).

\subsubsection{Sample characteristics}

Of the 444 adolescents in the MLSHA, 250 (56.3\%) were female. Over half (58.8\%) self-identified as white (non-Hispanic), 21.6\% as African-American, $4.3 \%$ as Hispanic, $3.1 \%$ as American Indian, $0.7 \%$ as Asian or Pacific Islander, $10.8 \%$ as bi-or multi-racial, and $0.7 \%$ did not respond. The youths ranged in age from 16 to 19 years (mean 17.33), and they ran away from home for the first time when they were an average of 13.45 years old (range $=2-18$ years). When asked where they had stayed the night before the interview, $40.3 \%$ stated a shelter or mission, $16.7 \%$ the home of a friend or acquaintance, $16.4 \%$ a foster or group home, $11.5 \%$ the home of a relative, $6.3 \%$ their own apartment (paying rent), $2.5 \%$ on the street or under a bridge, $1.4 \%$ in an abandoned house or squat, and $4.9 \%$ other.

In addition, many of the participants met lifetime criteria for one or more psychiatric diagnoses: major depressive episode (MDE) (30\%), conduct disorder $(76 \%)$, post-traumatic stress disorder $(36 \%)$, alcohol abuse $(44 \%)$, and drug abuse $(40 \%)$. Nearly one in five $(16 \%)$ attempted suicide in the year before the interview, and of these attempters, $52.1 \%$ made multiple lifetime attempts. Two-thirds of the youths reported thoughts of death or suicide in the year prior to the interview. Finally, lifetime exposure to attempted suicide by friends and family mem- 
bers was common (53.4 and 32.7\%, respectively); lifetime loss of a friend or family member to suicide also occurred frequently (30.4 and 13.7\%, respectively).

\subsection{Measures}

\subsubsection{Thoughts of death and suicide}

The four death-related items and four suicide-related items were adapted from two sources (Rudd, 1989; Yoder et al., 1998). Adolescents rated how often in the year prior to the interview that they had thoughts about being dead or committing suicide (see Table 1 for items and response categories). Subscales for thoughts of death and thoughts of suicide (four items each) were created by averaging the items.

\subsubsection{Sociodemographic variables}

Four variables measured sociodemographic characteristics: gender $(0=$ female, $1=$ male), race/ethnicity [0 = non-white (African-American, Hispanic, American Indian, Asian or Pacific Islander, or bi-or multi-racial), $1=$ white], sexual orientation [0 = heterosexual, 1 = non-heterosexual (gay, lesbian, bisexual, never thought about it, something else, or confused or unsure)], and age (in years).

\subsubsection{Neglect or abuse}

Three variables assessed adolescent experiences of neglect or abuse by an adult caretaker. Neglect contained 23 items [Cronbach's $\alpha=0.92$, average inter-item correlation $(\overline{\mathrm{r}})=0.34$ ] adapted from four sources (Bernstein et al., 1994; Brassard, Hart, \& Hardy, 1993; Shepard \& Campbell, 1992; US Department of Health and Human Services, 1988). Physical abuse had seven items $(\alpha=0.82, \bar{r}=0.40)$ from the Conflict Tactics Scale (Straus, 1979). Sexual abuse was an indicator variable $(0=$ no sexual abuse, 1 = an adult caretaker made them do something sexual or messed around with them sexually) adapted from Whitbeck and Simons (1990).

Table 1. Frequency distributions for death-and suicide-related items $(N=444)$

\begin{tabular}{lccc}
\hline In the past 12 months, how often have you... & $\begin{array}{c}\text { None of } \\
\text { the time (\%) }\end{array}$ & $\begin{array}{c}\text { Some of } \\
\text { the time (\%) }\end{array}$ & $\begin{array}{c}\text { All of } \\
\text { the time (\%) }\end{array}$ \\
\hline Death-related items & & & \\
[D1] Felt you would be better off if you were dead? 57.2 & 37.6 & 5.2 \\
[D2] Felt that life isn't worth living? & 54.7 & 36.7 & 8.6 \\
[D3] Felt like giving up because life was so bad? & 42.8 & 44.6 & 12.6 \\
[D4] Wished that your life would end? & 63.3 & 31.3 & 5.4 \\
Suicide-related items & & & \\
[S1] Thought about killing yourself? & 68.7 & 28.6 & 2.7 \\
[S2] Had plans to kill yourself? & 84.7 & 14.4 & 0.9 \\
[S3] Felt that your life will end in suicide? & 82.9 & 14.4 & 2.7 \\
[S4] Felt there is no solution to your problems & 76.1 & 20.7 & 2.9 \\
$\quad$ other than taking your own life?
\end{tabular}

a $0.2 \%(N=1)$ did not respond to this item 


\subsubsection{Victimization}

Two variables (both adapted from Whitbeck \& Simons, 1990) measured adolescent experiences of victimization while on their own. Physical victimization consisted of four items $(\alpha=0.71, \overline{\mathrm{r}}=0.38)$. Sexual victimization was an indicator variable $(0=$ not sexually victimized, $1=$ sexually assaulted or raped while on their own).

\subsubsection{Substance use}

Three variables assessed substance use in the year prior to the interview. Alcohol and marijuana were two ordinal variables $(0=$ never to $5=$ daily $)$, and hard drugs contained seven classes of drugs $(\alpha=0.84, \overline{\mathrm{r}}=0.43)$ : crank, other amphetamines, cocaine, opiates (e.g., heroin, morphine), hallucinogens (e.g., LSD, mescaline), barbiturates (e.g., downers, quaaludes), and inhalants (e.g., paint, glue).

\subsubsection{Psychological functioning}

Five variables measured adolescent psychological functioning. Externalization contained 30 items $(\alpha=0.86, \overline{\mathrm{r}}=0.17$ ) from the Youth Self-Report (Achenbach, 1991). Anger consisted of six items $(\alpha=0.87, \bar{r}=0.53)$ adapted from Oetting, Swaim, Edwards, and Beauvais (1989). Self-esteem contained ten items $(\alpha=0.88$, $\overline{\mathrm{r}}=0.42$ ) from the Rosenberg self-esteem scale (Rosenberg, 1965). Hopelessness had 20 items $(\alpha=0.77, \bar{r}=0.17)$ from the Hopelessness Scale for Children (Kazdin, French, Unis, Esveldt-Dawson, \& Sherick, 1983). Depressive symptoms consisted of 20 items $(\alpha=0.88, \bar{r}=0.27)$ from the Center for Epidemiologic Studies Depression scale (Radloff, 1977).

\subsubsection{Lifetime psychiatric diagnoses}

Five lifetime psychiatric diagnoses (each coded as $0=$ absent, $1=$ present) were measured. ${ }^{1}$ Conduct Disorder was assessed using the Diagnostic Interview Schedule for Children-Revised (DISC-R; Shaffer et al., 1993), and MDE, ${ }^{2}$ Post-Traumatic Stress Disorder, Alcohol Abuse, and Drug Abuse were assessed using the University of Michigan version of the Composite International Diagnostic Interview (UM-CIDI; Wittchen \& Kessler, 1994). The DISC-R and UMCIDI were based on criteria in the revised third edition of the Diagnostic and Statistical Manual of Mental Disorders (American Psychiatric Association, 1987), and both were intended for use by interviewers without clinical training. Researchers have reported good to excellent inter-rater and test-retest reliability and satisfactory validity on the DISC-R (Piacentini et al., 1993; Schwab-Stone et al., 1993; Shaffer et al., 1993) and on the CIDI, from which the UM-CIDI was derived (Wittchen, 1994).

1 Due to concerns about participant fatigue and time constraints, the number of psychiatric diagnoses was limited to those that were expected, based on previous research, to be most prevalent (Whitbeck, Johnson, Hoyt, \& Cauce, 2004).

2 The death-and suicide-related criteria for MDE were excluded in order to avoid artificially inflating the relationship of MDE with thoughts of death and thoughts of suicide. However, this did not affect the prevalence of MDE. 


\subsubsection{Suicide exposure and suicide attempt}

Suicide exposure was created by summing eight weighted items that assessed lifetime and past year exposure to attempted and completed suicide among friends and family members. The largest weight was assigned to past year exposure to completed suicide, and the smallest weight was assigned to lifetime exposure to attempted suicide. Finally, suicide attempt was an indicator variable $(0=$ not, 1 = participant attempted suicide in the year prior to the interview).

\subsection{Procedure}

\subsubsection{Missing cases and transformations}

A simple person-mean substitution method was used to handle missing values within multi-item scales - the mean-value of the remaining items was imputed for the missing items if at least half of the items had legitimate values. Missing value substitution was not used for the single-item variables. In addition, five of the multi-item scales (thoughts of death, thoughts of suicide, hard drugs, suicide exposure, and hopelessness) had excessive skewness and/or kurtosis, and the square root of the scales were used in the analyses.

\subsubsection{Analytic strategy}

The analyses were conducted in eight steps. First, frequency distributions for the death-and suicide-related items were examined. Second, for purposes of cross- validation, the sample was divided randomly into equal-sized exploratory and confirmatory samples (Floyd \& Widaman, 1995). Third, polychoric correlations among the death-and suicide-related items were estimated using PRELIS 2 (Jöreskog \& Sörbom, 2002) and examined for evidence of dimensionality in both samples.

Fourth, the exploratory sample was used to conduct EFA. Principal axis factoring $(\mathrm{PAF})$ with a promax rotation $(\kappa=4)$ was conducted in SPSS Version 12.0.2 using polychoric correlations. ${ }^{3}$ Evidence for dimensionality was assessed using the scree plot, parallel analysis, and Velicer's minimum average partial (MAP) test. ${ }^{4}$ Selection criteria for the number of factors include an "elbow" in the scree plot; in parallel analysis, the point at which the eigenvalues from the actual data are smaller than the eigenvalues from a randomly generated data set with the same number of cases and variables; and for the MAP test, the smallest value of Velicer's Average Squared Correlation (Netemeyer et al., 2003; O'Connor, 2000; Russell, 2002).

Fifth, the exploratory sample was used to computeSCs, which measure similarity in correlations among items in the same scale. Large SC-values (i.e., 0.80 or larger) constitute evidence for unidimensionality; large within-scale SCs for both subscales, coupled with a between-scale SC that is smaller than both within-scale SCs,

3 Principal axis factoring is typically used to find latent variables that account for relationships among variables, and principal components analysis (PCA) is usually used for data reduction (Floyd \& Widaman, 1995). Given the goals of this study, PAF was selected over PCA.

4 The commonly used eigenvalue $\geq 1$ rule is not appropriate when using principal axis factoring (Russell, 2002). 
provide support for multi-dimensionality (Steenbergen, 2000). The SCs were computed using polychoric correlations in UniSim, Version 1.0 (Steenbergen, 1999).

Sixth, the confirmatory sample was used to conduct CFA. The analyses were conducted using polychoric correlations and the Weighted Least Squares procedure in LISREL 8 (Jöreskog \& Sörbom, 2001). Evidence for dimensionality was assessed by comparing the fit of the one- and two-factor models ${ }^{5}$ using the $x^{2}$ statistic and descriptive fit indices. Criteria for a good-fitting model include a $\chi^{2}$ statistic $p>0.05$; RMSEA < 0.06; SRMR < 0.08; MOC > 0.90; and GFI*, NNFI, IFI, and CFI $>0.95$. Criteria for selecting the two-factor over the one-factor model (assuming a good- fitting two-factor model) include a significant difference between the model $\chi^{2}$ statistics $(p<0.05)$; smaller RMSEA, AIC, and SRMR; and larger MOC, GFI*, NNFI, IFI, and CFI (Marsh, Hau, \& Grayson, 2005).

Seventh, Cronbach's $\alpha$-values and average inter-item correlations ${ }^{6}$ were calculated to examine the internal consistency of the death-and suicide-related items. Finally, the full sample was used to assess external consistency by examining correlations of the thoughts of death and thoughts of suicide subscales with the other study variables. Evidence for unidimensionality is indicated by similar patterns of correlations for the two subscales (Carver, 1989). T-statistics were used to test for significant differences between the dependent correlations (Cohen \& Cohen, 1983), and given that multiple tests were performed, Type I error was controlled using an adaptive false discovery rate (AFDR) procedure, which has greater statistical power relative to familywise error control using a Bonferroni-based method (Benjamini \& Hochberg, 2000; Keselman, Cribbie, \& Holland, 2002).

\section{Results}

\subsection{Frequency distributions}

Table 1 presents frequency distributions for the death-and suicide-related items. Passive thoughts of death in the year prior to the interview were relatively common. Positive endorsements (some or all of the time) ranged from 36.7 (wished life would end) to $57.2 \%$ (felt like giving up) for individual items. Two-thirds $(66.0 \%)$ endorsed at least one death-related item. Active thoughts of suicide in the year prior to the interview were not as common. Positive endorsements ranged from 15.3 (suicidal plans) to $31.3 \%$ (thought about killing self) for individual items. Over one-third (37.2\%) endorsed at least one of the suicide-related items. In total, $66.7 \%$ endorsed at least one of the eight death-or suicide-related items.

\subsection{Polychoric correlations}

Table 2 contains polychoric correlations among the death-and suicide-related items in the exploratory and confirmatory subsamples. The correlations for both subsamples were all positive and relatively large (ranging from 0.49 to 0.91 ). In

5 Unidimensionality could also be assessed using a second-order CFA model (Rubio, BergWeger, \& Tebb, 2001), but this model is not identified with only two first-order latent constructs (Rindskopf \& Rose, 1988).

6 Strauss (2006) recommends reporting both Cronbach's $\alpha$ and the average inter-item correlation for assessing internal consistency reliability. 
Table 2. Polychoric correlations among death-and suicide-related items in the exploratory sample $(N=222$, below diagonal $)$ and the confirmatory sample $(N=221$, above diagonal $)$

\begin{tabular}{|c|c|c|c|c|c|c|c|c|}
\hline & D1 & D2 & D3 & D4 & S1 & $\mathrm{S} 2$ & S3 & S4 \\
\hline D1 & & 0.78 & 0.68 & 0.87 & 0.80 & 0.71 & 0.69 & 0.75 \\
\hline D2 & 0.80 & & 0.75 & 0.85 & 0.75 & 0.82 & 0.67 & 0.74 \\
\hline D3 & 0.67 & 0.79 & & 0.73 & 0.57 & 0.66 & 0.65 & 0.74 \\
\hline D4 & 0.84 & 0.78 & 0.71 & & 0.83 & 0.82 & 0.79 & 0.81 \\
\hline S1 & 0.84 & 0.76 & 0.64 & 0.82 & & 0.80 & 0.76 & 0.69 \\
\hline S2 & 0.75 & 0.65 & 0.55 & 0.67 & 0.93 & & 0.85 & 0.83 \\
\hline S3 & 0.67 & 0.66 & 0.49 & 0.78 & 0.87 & 0.72 & & 0.76 \\
\hline S4 & 0.79 & 0.70 & 0.59 & 0.91 & 0.84 & 0.78 & 0.76 & \\
\hline
\end{tabular}

addition, several of the between-subscale correlations (i.e., correlations of deathrelated with suicide-related items) exceed the within-subscale correlations. For instance, the correlation between S4 and D4 exceeds that of S4 with S1 and S3 in both subsamples. In fact, the largest correlation in the table (0.91) is between S4 and D4 in the exploratory sample. This is preliminary evidence that the deathand suicide-related items form one construct.

\subsection{Exploratory factor analysis and similarity coefficient results}

Table 3 presents the EFA results. The scree plot (not shown), parallel analysis, and MAP test suggest a one-factor solution. The factor pattern/structure loadings for the one-factor solution are relatively high (0.72-0.96). In addition, the SCs suggest a one-factor solution. The SC for the one-factor solution is 0.991 . For the twofactor solution, the within-scale SCs are 0.993 and 0.996, and the between-scale $\mathrm{SC}$ is 0.988 . Although the between-scale SC is smaller than the within-scale SCs, the difference is minimal. In sum, the EFA and SC results provide evidence that the death-and suicide-related items form one construct.

\subsection{Confirmatory factor analysis results}

Table 4 contains the fit indices for three alternative CFA models: the null model of independent variables $\left(\mathrm{M}_{0}\right)$, the one-factor model $\left(\mathrm{M}_{1}\right)$, and the correlated

Table 3. Exploratory factor analysis results $(N=222)$

\begin{tabular}{|c|c|c|c|c|c|c|c|}
\hline \multirow[t]{2}{*}{ Variable } & \multicolumn{3}{|c|}{ Parallel analysis } & \multicolumn{2}{|c|}{ MAP test } & \multicolumn{2}{|c|}{ One-factor solution } \\
\hline & $\begin{array}{l}\text { Factor } \\
\text { number }\end{array}$ & $\begin{array}{c}\text { Raw } \\
\text { eigenvalue }\end{array}$ & $\begin{array}{l}\text { Random } \\
\text { eigenvalue }\end{array}$ & $\begin{array}{l}\text { Factor } \\
\text { number }\end{array}$ & $\begin{array}{l}\text { Velicer's } \\
\text { ASC }\end{array}$ & $\begin{array}{l}\text { Factor } \\
\text { pattern }\end{array}$ & $\begin{array}{r}\text { Extraction } \\
\text { communality }\end{array}$ \\
\hline D1 & 1 & 6.08 & 1.35 & 0 & 0.56 & 0.89 & 0.80 \\
\hline D2 & 2 & 0.50 & 1.24 & 1 & 0.12 & 0.85 & 0.71 \\
\hline D3 & 3 & 0.28 & 1.14 & 2 & 0.14 & 0.72 & 0.52 \\
\hline D4 & 4 & 0.14 & 1.07 & 3 & 0.16 & 0.92 & 0.85 \\
\hline S1 & 5 & 0.04 & 1.00 & 4 & 0.21 & 0.96 & 0.92 \\
\hline S2 & 6 & -0.02 & 0.94 & 5 & 0.36 & 0.84 & 0.70 \\
\hline S3 & 7 & -0.04 & 0.88 & 6 & 0.56 & 0.82 & 0.67 \\
\hline S4 & 8 & -0.09 & 0.80 & 7 & 1.00 & 0.90 & 0.81 \\
\hline
\end{tabular}

Kaiser-Meyer-Olkin measure of sampling adequacy $=0.82$. Bartlett's test of sphericity $X^{2}(28)=2440, p<0.001$. Results based on principal axis factoring of polychoric correlations. Extraction sum of squared loadings was 5.977 and percent of variance explained was $74.72 \%$ 


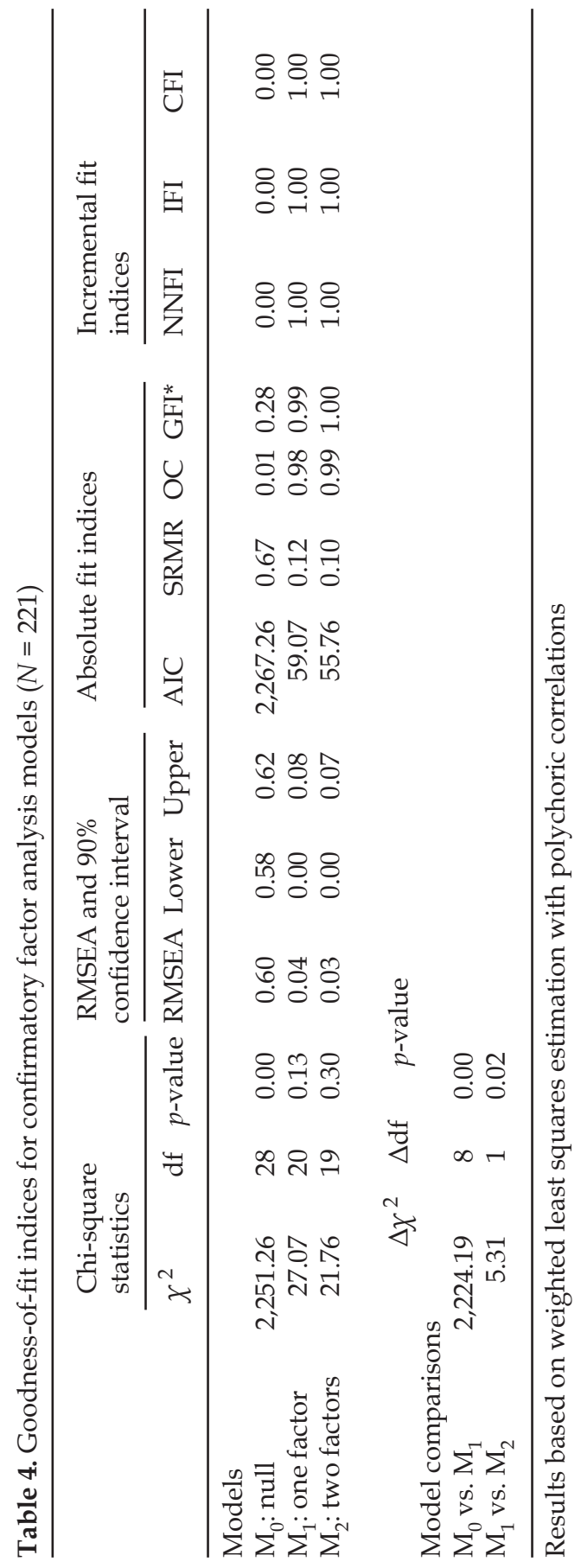


Table 5. Confirmatory factor analysis results $(N=221)$

\begin{tabular}{|c|c|c|c|c|c|c|c|c|}
\hline \multirow[b]{3}{*}{ Item } & \multicolumn{4}{|c|}{ One-factor solution } & \multicolumn{4}{|c|}{ Two-factor solution } \\
\hline & \multicolumn{2}{|c|}{ Factor loadings } & \multicolumn{2}{|c|}{ Error variances } & \multicolumn{2}{|c|}{ Factor loadings } & \multicolumn{2}{|c|}{ Error variances } \\
\hline & Value $^{\mathrm{a}}$ & $(\mathrm{SE})^{\mathrm{b}}$ & Value $^{a}$ & $(\mathrm{SE})^{\mathrm{b}}$ & Value $^{\mathrm{a}}$ & $(\mathrm{SE})^{\mathrm{b}}$ & Value $^{\mathrm{a}}$ & $(\mathrm{SE})^{\mathrm{b}}$ \\
\hline D1 & $0.91^{*}$ & $(0.02)$ & $0.17^{*}$ & $(0.08)$ & $0.91^{*}$ & $(0.02)$ & $0.17^{*}$ & $(0.08)$ \\
\hline D2 & $0.93^{*}$ & $(0.02)$ & 0.13 & $(0.08)$ & $0.94^{*}$ & $(0.02)$ & 0.12 & $(0.08)$ \\
\hline D3 & $0.86^{*}$ & $(0.04)$ & $0.26^{*}$ & $(0.10)$ & $0.86^{*}$ & $(0.04)$ & $0.26^{*}$ & $(0.10)$ \\
\hline D4 & $0.99^{*}$ & $(0.02)$ & 0.02 & $(0.08)$ & $0.98^{*}$ & $(0.02)$ & 0.03 & $(0.08)$ \\
\hline S1 & $0.94^{*}$ & $(0.03)$ & 0.11 & $(0.08)$ & $0.94^{*}$ & $(0.03)$ & 0.12 & $(0.08)$ \\
\hline S2 & $0.96^{*}$ & $(0.02)$ & 0.08 & $(0.08)$ & $0.96^{*}$ & $(0.02)$ & 0.07 & $(0.08)$ \\
\hline S3 & $0.96^{*}$ & $(0.03)$ & 0.09 & $(0.09)$ & $0.96^{*}$ & $(0.03)$ & 0.09 & $(0.09)$ \\
\hline S4 & $0.97^{*}$ & $(0.03)$ & 0.06 & $(0.08)$ & $0.97^{*}$ & $(0.03)$ & 0.05 & $(0.08)$ \\
\hline \multicolumn{5}{|c|}{ Factor correlation } & $0.95^{*}$ & $(0.02)$ & & \\
\hline
\end{tabular}

Results based on weighted least squares estimation with polychoric correlations

${ }^{a}$ Unstandardized and standardized estimates are equivalent

b Standard error

* Statistically significant at $p<0.05$ (two-tailed tests)

two-factor model $\left(\mathrm{M}_{2}\right)$. With the exception of the SRMR, the fit indices suggest that both $M_{1}$ and $M_{2}$ fit the data well. There is evidence that $M_{2}$ provides a superior fit to the data. In particular, the change in chi-square statistic is statistically significant $\left(\Delta \chi^{2}=5.31, \mathrm{df}=1, p=0.02\right)$, the RMSEA is smaller $(0.03$ vs. 0.04$)$ and has a narrower $90 \%$ confidence interval, the AIC is smaller (55.76 vs. 59.07 ), and MOC and GFI* are both larger (0.98 vs. 0.99 and 0.99 vs. 1.00$)$.

The standardized factor loadings and error variances for the one-and two-factor models are presented in Table 5. The factor loadings are relatively high (ranging from 0.86 to 0.99 ) and do not differ much between the models. The inter-factor correlation, however, is substantial (0.95). In sum, the fit indices suggest that the death- and suicide-related items are measuring separate constructs, but the large inter-factor correlation indicates that the eight items are, practically speaking, measuring one construct.

\subsection{Internal and external consistency}

Using the full sample $(N=444)$, there is evidence for good internal consistency for all eight items [Cronbach's $\alpha=0.95$, average inter-item correlation $(\mathrm{r})=0.70$ ], the four death-related items $(\alpha=0.92, \overline{\mathrm{r}}=0.74)$, and the four suicide-related items $(\alpha=0.94, \bar{r}=0.80)$. Finally, Table 6 contains Pearson correlations of the thoughts of death and thoughts of suicide subscales with other variables for the full sample. Most of the correlations are statistically significant and in the expected directions. The thoughts of death and thoughts of suicide subscales are highly intercorrelated (not shown in Table 6; $\overline{\mathrm{r}}=0.71, p<0.001$ ). After controlling for Type I error, most of the correlations are not significantly different for the two subscales. Nevertheless, there are two notable exceptions. First, the correlation of depressive symptoms with thoughts of death is higher than is the correlation with thoughts of suicide ( 0.51 and 0.38 , respectively). Second, the correlation of suicide attempt with thoughts of death is lower than is the correlation with thoughts of suicide (0.40 and 0.58 , respectively). 
Table 6. Comparison of pearson correlations for thoughts of death and suicide subscales with other variables $(N=444)$

\begin{tabular}{|c|c|c|c|c|c|}
\hline \multirow[t]{2}{*}{ Variable } & \multicolumn{3}{|c|}{ Correlations $^{\mathrm{a}}$} & \multicolumn{2}{|c|}{$\begin{array}{l}\text { Comparisons of } \\
\text { dependent correlations }\end{array}$} \\
\hline & Thoughts & f death & Thoughts of suicide & T-statistic & $p$-value \\
\hline \multicolumn{6}{|l|}{ Sociodemographic } \\
\hline Gender & & $-0.08+$ & -0.06 & -0.80 & 0.42 \\
\hline Race/ethnicity & & -0.04 & 0.02 & -1.63 & 0.11 \\
\hline Sexual orientation & & $0.08+$ & $0.13^{* *}$ & -1.31 & 0.19 \\
\hline Age & & 0.06 & $0.08+$ & -0.55 & 0.58 \\
\hline \multicolumn{6}{|c|}{ Family neglect and abuse } \\
\hline Neglect & & $0.24^{* * *}$ & $0.23^{* * *}$ & 0.34 & 0.73 \\
\hline Physical abuse & & $0.18^{* * *}$ & $0.17^{* * *}$ & 0.28 & 0.78 \\
\hline Sexual abuse & & $0.16^{* * *}$ & $0.19^{* * *}$ & -0.82 & 0.41 \\
\hline \multicolumn{6}{|l|}{ Street victimization } \\
\hline Physical victimizatic & & $0.15^{\star *}$ & $0.11^{*}$ & 0.89 & 0.37 \\
\hline Sexual victimization & & $0.14^{* *}$ & $0.15^{\star *}$ & -0.08 & 0.93 \\
\hline \multicolumn{6}{|l|}{ Substance use } \\
\hline Alcohol & & $0.13^{* *}$ & $0.12^{*}$ & 0.22 & 0.82 \\
\hline Marijuana & & 0.08 & 0.06 & 0.33 & 0.74 \\
\hline Hard drugs & & $0.15^{* * *}$ & $0.16^{* * *}$ & -0.34 & 0.74 \\
\hline \multicolumn{6}{|l|}{ Psychological } \\
\hline Externalization & & $0.25^{* * *}$ & $0.17^{* * *}$ & 2.40 & 0.02 \\
\hline Anger & & $0.36^{* * *}$ & $0.28^{* * *}$ & 2.37 & 0.02 \\
\hline Self-esteem & & $-0.51^{* * *}$ & $-0.45^{\star * *}$ & -1.81 & 0.07 \\
\hline Hopelessness & & $0.36^{* * *}$ & $0.32^{* * *}$ & 1.31 & 0.19 \\
\hline Depressive sympton & & $0.51^{* * *}$ & $0.38^{* * *}$ & 3.93 & $0.00 \dagger$ \\
\hline \multicolumn{6}{|c|}{ Lifetime psychiatric diagnoses $^{c}$} \\
\hline Major depressive ep & isode & $0.21^{* * *}$ & $0.19^{* * *}$ & 0.55 & 0.58 \\
\hline Conduct disorder & & $0.17^{* *}$ & $0.08+$ & 2.33 & 0.02 \\
\hline Post-traumatic stres & s disorder & $0.22^{* * *}$ & $0.18^{* * *}$ & 0.89 & 0.38 \\
\hline Alcohol abuse & & 0.08 & $0.08+$ & -0.16 & 0.87 \\
\hline Drug abuse & & $0.10^{*}$ & $0.12^{*}$ & -0.49 & 0.62 \\
\hline \multicolumn{6}{|l|}{ Suicidality } \\
\hline Suicide exposure & & $0.14^{* *}$ & $0.18^{* * *}$ & -1.03 & -6.14 \\
\hline Suicide attempt & & $0.40^{* * *}$ & $0.58^{* * *}$ & 0.30 & $0.00 \dagger$ \\
\hline
\end{tabular}

a Tests of significance for individual correlations indicated by $+0.10 \leq p<0.05,{ }^{*} 0.05 \leq p<0.01$, ** $0.01 \leq p<0.001$, and ${ }^{* * *} p \leq 0.001$ (two-tailed tests)

${ }^{\mathrm{b}}$ Results of $t$-tests for dependent correlations (Cohen \& Cohen, 1983). $p$-values with $†$ indicate significant differences between correlations after controlling for Type I error using the adaptive false discovery rate (AFDR) procedure (Benjamini \& Hochberg, 2000; Keselman et al., 2002)

c Based on $N=428$ who completed the second diagnostic interview

In sum, external consistency results provide some evidence that thoughts of death and thoughts of suicide are separate constructs.

\section{Discussion}

\subsection{Summary}

This study examined evidence for dimensionality of thoughts of death and suicide using a sample of 444 homeless adolescents. Thoughts of death and suicide 
in the year prior to the interview was relatively common; over two-thirds (66.7\%) of the adolescents positively endorsed at least one of the eight items. However, evidence regarding dimensionality of the death-and suicide-related items was mixed. The EFA results, SCs, and large inter-factor correlation in the two-factor CFA model (0.95) supported the existence of one construct. On the other hand, the CFA and external consistency results indicated two constructs. The EFA results were consistent with previous psychometric studies (Holi et al., 2005; Lewinsohn et al., 1996; Pfeffer et al., 2000; Pinto et al., 1997; Tatman et al., 1993). Although the CFA results were consistent with two previous studies that used EFA (Reynolds, 1988, 1990), they were not consistent with other studies that used CFA (Harlow et al., 1986; Light et al., 2003; Osman et al., 2002, 2003; Stewart et al., 2006).

\subsection{Weaknesses}

Before discussing the substantive conclusions, three issues regarding the analyses and sample should be addressed. First, content validity is fairly low. The items in the analyses capture narrow aspects of the constructs, and future attempts to replicate and extend these analyses should include a broader spectrum of items. For instance, studies on thoughts of death among the elderly have included items such as not taking care of one's health, eating too little, or failing to take needed medication (Szanto et al., 1996). In addition, the Suicidal Ideation Questionnaire (Reynolds, 1988) contains items that capture general thoughts about death and committing suicide, specific thoughts about committing suicide (methods, time, and place), thoughts about preparing for suicide (writing a suicide note or will), and reasons for committing suicide (solve problems, others would be better off, or others would be happier).

The second issue involves the high correlations ( 0.49 and above) among the death-and suicide-related items. Clark and Watson (1995) indicate that inter-item correlations should fall between 0.15 and 0.50 to ensure unidimensionality; correlations exceeding 0.50 imply item redundancy. There are three potential reasons for the large inter-item correlations. First, the polychoric correlations might be overly inflated relative to their corresponding Pearson correlations (Olsson, 1979). This explanation can be ruled out because most of the Pearson correlations also exceeded $0.50 .{ }^{7}$ Second, the large correlations might be due to low-content validitythe items are from narrowly defined domains within the constructs. This explanation, while highly plausible, cannot be confirmed because the analyses did not include items that measure other aspects of thoughts of death and suicide. Third, the correlations might be large due to the high-risk nature of the sample. As evidence for this assertion, one study of severely suicidal young adults indicated that depression, hopelessness, and suicidal ideation were highly intercorrelated and essentially formed one construct (Shahar, Bareket, Rudd, \& Joiner, 2006).

The third issue involves weaknesses in the sample. First, the analyses were based on single-person reports. Second, the results may not generalize to other homeless adolescents. Although participants were selected from several Midwestern cities, research has indicated that characteristics of homeless youths dif-

7 All of the analyses were repeated using Pearson correlations, and the SCs and the factor loadings in all of the exploratory and CFA models were lower. Nonetheless, the substantive conclusions based on the Pearson correlations were the same as they were for the polychoric correlations. 
fer by region of the country (Thompson, Maguin, \& Pollio, 2003), which might lead to disparate results based on samples of homeless adolescents from other geographic areas. Finally, the data are from a non-probability sample, and statistically speaking, a probability sample is preferable. However, the population of interest is highly unstable and not very well defined (Whitbeck \& Hoyt, 1999), which makes it impossible to create a sampling frame and to determine a probability of selection.

\section{Conclusion}

The results of this study should be interpreted with appropriate caution, and they await replication in other samples of adolescents before drawing firm conclusions about the dimensionality of thoughts of death and suicide. Nonetheless, the mixed results might be reconciled by considering the suicidal process in which suicidality is conceived as a continuum from thoughts of death to suicidal ideation, suicide attempts, and completed suicide (Neeleman, de Graaf, \& Vollebergh, 2004). The stronger correlation of thoughts of death with depressive symptoms suggests that thoughts of death represent more general feelings of distressand hence are lower on the suicidality continuum - than do thoughts of suicide. Moreover, the stronger correlation of thoughts of suicide with a suicide attempt suggests that thoughts of suicide are higher on the suicidality continuum.

The study findings also suggest potential directions for future measurement and research concerning thoughts of death and suicide. In particular, given the large correlation between the two constructs, studies of suicidal ideation more generally might consider thoughts of death and suicide as one construct (e.g., Lewinsohn et al., 1996). On the other hand, studies of the suicidal process might consider thoughts of death and thoughts of suicide as separate constructs (e.g., Neeleman et al., 2004). Further insight into the suicidal continuum could be gained by comparing youths who have thoughts of death only with those who have thoughts of suicide. Such comparisons have received minimal attention in the literature on adolescent suicidality (e.g., Deykin \& Buka, 1994; Foley, Goldston, Costello, \& Angold, 2006).

Finally, the present research has practical implications for people who work with homeless adolescents. These young people are experiencing serious distress as indicated by the high prevalence of suicide attempts, thoughts of death and suicide, and psychiatric disorders. This suggests the importance of careful screening for psychiatric disorders and suicidality, and brief screening tools with established reliability and validity (e.g., Lewinsohn et al., 1996) might work well. Youths who express thoughts of death should be taken seriously because they are likely experiencing severe problems and engaging in potentially life-threatening behaviors. Actively suicidal adolescents should be offered appropriate therapeutic interventions that draw on their strengths (Karabanow \& Clement, 2004) so that future suicidal behaviors might be prevented.

\section{Acknowledgments}

The Midwest Longitudinal Study of Homeless Adolescents was supported by the National Institute of Mental Health (MH57110), Les B. Whitbeck, Principal Investigator. Thank you to Kurt Johnson and Elizabeth Fisher for comments and help on earlier drafts of this paper. 


\section{References}

Achenbach, T. M. (1991). Manual for the youth self-report and 1991 profile. Burlington: University of Vermont.

American Psychiatric Association. (1987). Diagnostic and statistical manual of mental disorders (3rd ed., revised). Washington, DC: APA.

Benjamini, Y., \& Hochberg, Y. (2000). On the adaptive control of the false discovery rate in multiple testing with independent statistics. Journal of Educational and Behavioral Statistics, 25, $60-83$.

Bernstein, D. P., Fink, L., Handelsman, L., Foote, J., Lovejoy, M., Wenzel, K., et al. (1994). Initial reliability and validity of a new retrospective measure of child abuse and neglect. American Journal of Psychiatry, 151, 1132-1136.

Brassard, M. R., Hart, S. N., \& Hardy, D. B. (1993). The psychological maltreatment rating scales. Child Abuse And Neglect, 17, 715-729.

Carver, C. S. (1989). How should multifaceted personality constructs be tested? Issues illustrated by self-monitoring, attributional style, and hardiness. Journal of Personality and Social Psychology, 56, 577-585.

Clark, L. A., \& Watson, D. (1995). Constructing validity: Basic issues in objective scale development. Psychological Assessment, 7, 309-319.

Cohen, J., \& Cohen, P. (1983). Applied multiple regression/correlation analysis for the behavioral sciences. (2nd ed.). Hillsdale, NJ: Lawrence Erlbaum.

Deykin, E. Y., \& Buka, S. L. (1994). Suicidal ideation and attempts among chemically dependent adolescents. American Journal of Public Health, 84, 634-639.

Evans, E., Hawton, K., Rodham, K., \& Deeks, J. (2005). The prevalence of suicidal phenomena in adolescents: A systematic review of population-based studies. Suicide and Life-Threatening Behavior, 35, 239-250.

Floyd, F. J., \& Widaman, K. F. (1995). Factor analysis in the development and refinement of clinical assessment instruments. Psychological Assessment, 7, 286-299.

Foley, D. L., Goldston, D. B., Costello, E. J., \& Angold, A. (2006). Proximal psychiatric risk factors for suicidality in youth. Archives of General Psychiatry, 63, 1017-1024.

Gerbing, D. W., \& Anderson, J. C. (1988). An updated paradigm for scale development incorporating unidimensionality and its assessment. Journal of Marketing Research, 25, 186-192.

Goldston, D. B. (2000). Assessment of suicidal behaviors and risk among children and adolescents. Technical report submitted to NIMH under Contract No. 263-MD-909995.

Harlow, L. L., Newcomb, M. D., \& Bentler, P. M. (1986). Depression, self-derogation, substance use, and suicide ideation: Lack of purpose in life as a mediational factor. Journal of Clinical Psychology, 42, 5-21.

Holi, M. M., Pelkonen, M., Karlsson, L., Kiviruusu, O., Ruuttu, T., Heilä, H., et al. (2005). Psychometric properties and clinical utility of the Scale for Suicidal Ideation (SSI) in adolescents. $B M C$ Psychiatry, 5, 1-8.

Hoyert, D. L., Heron, M. P., Murphy, S. L., \& Kung, H.-C. (2006). Deaths: Final data for 2003. National Vital Statistics Report, 54. Hyattsville, MD: National Center for Health Statistics.

Jöreskog, K. G., \& Sörbom, D. (2001). LISREL 8: User's reference guide. Lincolnwood, IL: Scientific Software International.

Jöreskog, K. G., \& Sörbom, D. (2002). PRELIS 2: User's reference guide. Lincolnwood, IL: Scientific Software International.

Karabanow, J., \& Clement, P. (2004). Interventions with street youth: A commentary on the practice-based research literature. Brief Treatment and Crisis Intervention, 4, 93-108.

Kazdin, A. E., French, N. H., Unis, A. S., Esveldt-Dawson, K., \& Sherick, R. B. (1983). Hopelessness, depression, and suicidal intent among psychiatrically disturbed inpatient children. Journal of Consulting and Clinical Psychology, 51, 504-510.

Keselman, H. J., Cribbie, R., \& Holland, B. (2002). Controlling the rate of Type I error over a large set of statistical tests. British Journal of Mathematical and Statistical Psychology, 55, 27-39.

Kidd, S. A. (2006). Factors precipitating suicidality among homeless youth: A quantitative followup. Youth and Society, 37, 393-422.

Klimes-Dougan, B. (1998). Screening for suicidal ideation in children and adolescents: Methodological considerations. Journal of Adolescence, 21, 435-444.

Lester, D. (1998). Comment on the Positive and Negative Suicide Ideation scale. Psychological Reports, 82, 1394. 
Lewinsohn, P. M., Rohde, P., \& Seeley, J. R. (1996). Adolescent suicidal ideation and attempts: Prevalence, risk factors, and clinical implications. Clinical Psychology, 3, 25-46.

Light, J. M., Grube, J. W., Madden, P. A., \& Gover, J. (2003). Adolescent alcohol use and suicidal ideation: A nonrecursive model. Addictive Behaviors, 28, 705-724.

Marsh, H. W., Hau, K.-T., \& Grayson, D. (2005). Goodness of fit in structural equation models. In A. Maydeu-Olivares, \& J. J. McArdle (Eds.), Contemporary psychometrics: A festschrift for Roderick P. McDonald (pp. 275-340). Mahwah, NJ: Lawrence Erlbaum.

Neeleman, J., de Graaf, R., \& Vollebergh, W. (2004). The suicidal process; prospective comparison between early and later stages. Journal of Affective Disorders, 82, 43-52.

Netemeyer, R. G., Bearden, W. O., \& Sharma, S. (2003). Scaling procedures: Issues and applications. Thousand Oaks, CA: Sage.

O'Carroll, P. W., Berman, A. L., Maris, R. W., Moscicki, E. K., Tanney, B. L., \& Silverman, M. M. (1996). Beyond the tower of Babel: A nomenclature for suicidology. Suicide and Life-Threatening Behavior, 26, 237-252.

O'Connor, B. P. (2000). SPSS and SAS programs for determining the number of components using parallel analysis and Velicer's MAP test. Behavior Research Methods, Instruments, and Computers, 32, 396-402.

Oetting, E. R., Swaim, R. C., Edwards, R. W., \& Beauvais, F. (1989). Indian and Anglo adolescent alcohol use and emotional distress: Path models. American Journal of Drug and Alcohol Abuse, $15,153-172$.

Olsson, U. (1979). Maximum likelihood estimation of the polychoric correlation coefficient. Psychometrika, 44, 443-460.

Osman, A., Barrios, F. X., Gutierrez, P. M., Wrangham, J. J., Kopper, B. A., Truelove, R. S., \& Linden, S. C. (2002). The Positive and Negative Suicide Ideation (PANSI) inventory: Psychometric evaluation with adolescent psychiatric inpatient samples. Journal of Personality Assessment, $79,512-530$.

Osman, A., Gutierrez, P. M., Jiandani, J., Kopper, B. A., Barrios, F. X., Linden, S. C., \& Truelove, R. S. (2003). A preliminary validation of the Positive and Negative Suicide Ideation (PANSI) inventory with normal adolescent samples. Journal of Clinical Psychology, 59, 493-512.

Osman, A., Gutierrez, P. M., Kopper, B. A., Barrios, F. X., \& Chiros, C. E. (1998). The positive and negative suicide ideation inventory: Development and validation. Psychological Reports, $82,783-793$.

Pfeffer, C. R., Jiang, H., \& Kakuma, T. (2000). Child-Adolescent Suicidal Potential Index (CASPI): A screen for risk for early onset suicidal behavior. Psychological Assessment, 12, 304-318.

Piacentini, J., Shaffer, D., Fisher, P., Schwab-Stone, M., Davies, M., \& Gioia, P. (1993). The Diagnostic Interview Schedule for Children-Revised version (DISC-R): III. Concurrent criterion validity. Journal of the American Academy of Child and Adolescent Psychiatry, 32, 658-665.

Pinto, A., Whisman, M. A., \& McCoy, K. J. M. (1997). Suicidal ideation in adolescents: Psychometric properties of the suicidal ideation questionnaire in a clinical sample. Psychological Assessment, 9, 63-66.

Radloff, L. S. (1977). The CES-D scale: A self-report depression scale for research in the general population. Applied Psychological Measurement, 1, 385-401.

Reynolds, W. M. (1988). Suicidal Ideation Questionnaire: Professional manual. Lutz, FL: Psychological Assessment Resources.

Reynolds, W. M. (1990). Development of a semistructured clinical interview for suicidal behaviors in adolescents. Psychological Assessment, 2, 382-390.

Rindskopf, D., \& Rose, T. (1988). Some theory and applications of confirmatory second-order factor analysis. Multivariate Behavioral Research, 23, 51-67.

Rohde, P., Noell, J., Ochs, L., \& Seeley, J. R. (2001). Depression, suicidal ideation, and STD-related risk in homeless older adolescents. Journal of Adolescence, 24, 447-460.

Rosenberg, M. (1965). Society and the adolescent self-image. Princeton, NJ: Princeton University Press.

Rubio, D. M., Berg-Weger, M., \& Tebb, S. S. (2001). Using structural equation modeling to test for multidimensionality. Structural Equation Modeling, 8, 613-626.

Rudd, M. D. (1989). The prevalence of suicidal ideation among college students. Suicide and LifeThreatening Behavior, 19, 173-183.

Russell, D. W. (2002). In search of underlying dimensions: The use (and abuse) of factor analysis in Personality and social psychology bulletin. Personality and Social Psychology Bulletin, 28, 1629- 1646. 
Schutt, R. K., Meschede, T., \& Rierdan, J. (1994). Distress, suicidal thoughts, and social support among homeless adults. Journal of Health and Social Behavior, 35, 134-142.

Schwab-Stone, M., Fisher, P., Piacentini, J., Shaffer, D., Davies, M., \& Briggs, M. (1993). The Diagnostic Interview Schedule for Children-Revised version (DISC-R): II. Test-retest reliability. Journal of the American Academy of Child and Adolescent Psychiatry, 32, 651-657.

Shaffer, D., Schwab-Stone, M., Fisher, P., Cohen, P., Piacentini, J., Davies, M., et al. (1993). The Diagnostic Interview Schedule for Children-Revised version (DISC-R): I. Preparation, field testing, interrater reliability, and acceptability. Journal of the American Academy of Child and Adolescent Psychiatry, 32, 643-650.

Shahar, G., Bareket, L., Rudd, M. D., \& Joiner, T. E. (2006). In severely suicidal young adults, hopelessness, depressive symptoms, and suicidal ideation constitute a single syndrome. Psychological Medicine, 36, 913-922.

Shepard, M. F., \& Campbell, J. A. (1992). The abusive behavior inventory: A measure of psychological and physical abuse. Journal of Interpersonal Violence, 7, 291-305.

Steenbergen, M. R. (1999). UniSim: A program for assessing scale unidimensionality (Version 1.0) [Computer software].

Steenbergen, M. R. (2000). Item similarity in scale analysis. Political Analysis, 8, 261-283.

Stewart, S. M., Felice, E., Claassen, C., Kennard, B. D., Lee, P. W. H., \& Emslie, G. J. (2006). Adolescent suicide attempters in Hong Kong and the United States. Social Science and Medicine, 63, 296-306.

Straus, M. A. (1979). Measuring intrafamily conflict and violence: The conflict tactics (CT) scale. Journal of Marriage and the Family, 41, 75-88.

Strauss, M. E. (2006). Editor's note: Reporting internal consistency reliability coefficients. Psychological Assessment, 18, ii.

Szanto, K., Reynolds, C. F., Frank, E., Stack, J., Fasiczka, A. L., Miller, M., et al. (1996). Suicide in elderly depressed patients: Is active vs. passive suicidal ideation a clinically valid distinction? American Journal of Geriatric Psychiatry, 4, 197-207.

Tatman, S. M., Greene, A. L., \& Karr, L. C. (1993). Use of the Suicide Probability Scale (SPS) with adolescents. Suicide and Life-Threatening Behavior, 23, 188-203.

Thompson, S. J., Maguin, E., \& Pollio, D. E. (2003). National and regional differences among runaway youth using federally-funded crisis services. Journal of Social Science Research, 30,1-17.

Unger, J. B., Kipke, M. D., Simon, T. R., Montgomery, S. B., \& Johnson, C. J. (1997). Homeless youths and young adults in Los Angeles: Prevalence of mental health problems and the relationship between mental health and substance abuse disorders. American Journal of Community Psychology, 25, 371-394.

US Department of Health and Human Services. (1988). Study of national incidence and prevalence of child abuse and neglect. Washington, DC: US Government Printing Office.

US Department of Health and Human Services. (2001). Protection of human subjects. Code of Federal Regulations (45 CFR § 46 et seq.). National Institutes of Health, Office of Protection from Research Risks.

Valois, R. F., Zullig, K. J., Huebner, E. S., \& Drane, J. W. (2004). Life satisfaction and suicide among high school adolescents. Social Indicators Research, 66, 81-105.

Whitbeck, L. B., \& Hoyt, D. R. (1999). Nowhere to grow: Homeless and runaway adolescents and their families. New York: Aldine de Gruyter.

Whitbeck, L. B., Johnson, K. D., Hoyt, D. R., \& Cauce, A. M. (2004). The missing psychotic disorders: Response. Journal of Adolescent Health, 35, 433.

Whitbeck, L. B., \& Simons, R. L. (1990). Life on the streets: The victimization of runaway and homeless adolescents. Youth and Society, 22, 108-125.

Wittchen, H.-U. (1994). Reliability and validity studies of the WHO-Composite International Diagnostic Interview (CIDI): A critical review. Journal of Psychiatric Research, 28, 57-84.

Wittchen, H.-U., \& Kessler, R. C. (1994). Modifications of the CIDI in the national comorbidity survey: The development of the UM-CIDI (NCS Working Paper \#2). Ann Arbor: Institute for Social Research, The University of Michigan.

Yoder, K. A. (1999). Comparing suicide attempters, suicide ideators, and nonsuicidal homeless and runaway adolescents. Suicide and Life-Threatening Behavior, 29, 25-36.

Yoder, K. A., Hoyt, D. R., \& Whitbeck, L. B. (1998). Suicidal behavior among homeless and runaway adolescents. Journal of Youth and Adolescence, 27, 753-771. 